\section{PENICILLIN TREATMENT}

A SPECIAL issue of the British Journal of Surgery (32, 105-224, 1944. 12s. 6d. net) is devoted to reports by British and United States medical men on the treatment with penicillin of battle casualties which has been carried out during the present War. Everybody who is at all interested in penicillin should read this valuable and beautifully produced record. It is only two years, Major-General $\mathrm{L}$. T. Poole explains in his foreword, since Sir Howard Florey offered to the British War Ottce a small quantity of penicillin for trial in the Middle East. This was successfully flown out there, in spite of the difficulties of communications at that time. The strength of the first batches received by the Army varied from 30 to 40 Oxford units per mgm. Nowadays some of the preparations used have a strength of about 1,600 units per mgm. This is one measure of the progress made in this short period. The progress in production may be gauged by the fact that the Penicillin Team sent to North Africa in May 1943 was equipped with ten million units, whereas later it was possible to send by air regularly to Italy twenty million units a day.

Penicillin treatment is not, of course, to be lightly undertaken. Everywhere in this record of its use the necessity for the training of teams of workers for its application is emphasized. Sir Howard Florey and M. A. Jennings deal with the general principles of the treatment. They summarize the properties of penicillin, which Sir Howard Florey has already described in Nature (Jan. 8, p. 40, 1944). Modern methods of its administration are less well known and are here described by Sir Howe rd and M. A. Jennings and by other contributors. The rapid absorption and elimination of penicillin must always be borne in mind. Relatively large doses must be given and these must be frequently repeated. A continuous concentration of the drug must be maintained in contact with all the infected tissues. For systemic administration penicillin is usually given by intramuscular or subcutaneous injection. After intramuscular injection the maximum concentration in the blood is reached after fifteen minutes, so that little is gained by intravenous administration. Absorption from subcutaneous injection is somewhat slower. Excretion in the urine begins as soon as the penicillin reaches the blood. As a rule, in the fourth hour after a dose of 15,000 units, a bacteriostatic concentration no longer exists in the blood, so that the dose should be repeated every three hours. Excretion is so rapid that there is probably no advantage in increasing the dose of 15,000 units originally established by the Floreys as the generally effective dose. The same total dose can be given by a continuous intravenous or intramuscular drip or by continuous subcutaneous infusion. For local administration, penicillin in the form of a powder, a solution or in creams can be used. Brigadier R. W. Mackenna (The Lancet, 314, Sept. 2, 1944) has devised a dosimetric spray for the treatment of skin diseases.

Because penicillin must be brought into contact with every part of the infected tissues, all dead tissue must be removed. Penicillin is not, therefore, a substitute for surgery, and most of the surgeons contributing to this symposium emphasize this fact. For the same reason too much should not be expected from it when certain kinds of severe injury are being treated. Major R. Furlong and Major J. M. P. Clark, for example, reporting on the treatment of open fractures of the femur, conclude that the penicillin treatment given by them did not control sepsis fully; but this kind of battle casualty presents the surgeon with great difficulties. It may, for example, be difficult to obtain adequate drainage of all parts of such extensive and complex injuries as these, and, as the authors remark, "penicillin cannot be expected to clean Augean stables". Lieut.-Colonel Jeffrey, who succeeded Lieut.-Colonel Ian Fraser as penicillin surgical officer in North Africa and Italy when the latter was invalided home, reports, however, in his article on battle fractures in Italy, that penicillin, in his experience, very largely controlled the infection. Without the assurance that this would be so, the necessary radical surgical treatment would not have been justified in such cases as compound fractures more than twelve hours old. The authors of both these articles on battle fractures record a reduction of mortality and fewer losses of limbs as the result of the use of penicillin.

The hastening of healing by early closure of the wound and the instillation of penicillin through fine rubber tubes placed in the wound is discussed by Lieut.-Colonels F. H. Bentley and J. J. Mason Brown. Photographs illustrate the method of doing this. Penicillin may also be injected with a needle. Like some other substances, penicillin passes only slowly from the blood into the cerebro-spinal spaces, and into the pleural and probably the joint cavities also. For meningitis, Sir Howard Florey and M. A. Jennings state that intrathecal injection by the lumbar route or into the lateral ventricles of the brain is most effective. Fleming and others have shown that this method maintains a bacteriostatic concentration in the cerebro-spinal fluid. The article by Brigadier Hugh Cairns deals with this method for the treatment of wounds of the head and spine, to which penicillin can be applied either as a powder, as a solution instilled through rubber tubes in the wound, by systemic routes or by injection of it by the lumbar route or into the lateral ventricles of the brain. Sulphadiazine or sulphamezathine are, he says, useful additional means for the prevention or prophylaxis of meningitis. One is reminded here of the claims made by some Russian workers that tetanus can be successfully treated by a similar injection of tetanus antitoxin into the lateral ventricles of the brain and the cerebrospinal spaces, the so-called blood-brain barrier being thus overcome. Brigadier Cairns, like his colleagues, emphasizes the need for "careful surgical toilet" in addition to the penicillin. Two articles describe the use of penicillin for treatment of wounds of the chest, and the value of penicillin is agreed, although its value for cases of hxmothorax is less certain.

The two articles on the treatment of gas gangrene indicate that more work is required on the treatment of this condition with penicillin. In one of these articles, which is illustrated by photographs in colour of the progress of battle wounds, Col. Elliott C. Cutler and Major. W. R. Sandusky, United States Army, record that penicillin did not prevent the development of gas gangrene in seven cases treated locally and parenterally. This number of cases is, they conclude, too small to enable them to assess the real influence of penicillin on gas gangrene, but they think that surgical treatment is the main factor in the prophylaxis and treatment. Lieut.-Colonel J. S. Jeffrey and Major Scott Thomson report on thirtythree cases of gas gangrene in Italy and conclude 
that penicillin was definitely useful. The causative organism in Italy was $C l$. welchii.

The use of penicillin for the treatment of venereal disease is described in two articles. Major J. N. Robinson, United States Army, concludes that "penicillip is the most effective agent we have for treating all types of gonorrhøa. If the supply were unlimited, it would be the therapy of choice". Lieut.Colonel D. M. Pillsbury and Major C. S. Wise, United States Army, report their confirmation of earlier work which showed that penicillin rapidly kills the spirochætes which cause syphilis and causes early regression of syphilitic symptoms; the immediate effects of penicillin are, they think, better than those of the arsenical preparations. The bibliography, which contains, the editors say, references to all the previous published work on penicillin, refers to work on other spirochætal infections, such as relapsing fever.

The low toxicity of penicillin, especially of the purer forms of it now available, is one of its most remarkable features. It is almost certain, say Sir Howard Florey and M. A. Jennings, that such clinical reactions as are seen in some cases are due to the impurities which are present in all preparations of penicillin. There is all the more reason for the warnings which have been issued against the use of 'home-made penicillin' and preparations of other fungi. One of the outstanding features of this symposium is, indeed, the insistence in more than one article of the need for careful technique, which should be carried out by specially trained teams, and for the control of the treatment by the bacteriologist. Penicillin has, moreover, certain definite limitations which are indicated by Sir Howard Florey and M. A. Jennings and by Lieut.-Colonel J. S. Jeffrey. Certain organisms are resistant to it, nor can penicillin act on organisms susceptible to it when these are in dead tissue or in the centre of abscesses or masses of pus ; it cannot affect bacterial toxins either. Ignorance or neglect of these facts, inadequate dosage and lack of proper supervision of the technique may result in disappointment. There has, however, been little tendency to neglect adequate surgery or to rely too much upon penicillin. The bacteriological control necessary is well described by Prof. L. P. Garrod and N. G. Heatléy in their account of the diagnosis of bacteria in wounds, of the standardization of the Oxford unit (the unit of potency) and the methods of assay of penicillin used for treatment or present in exudates or in the blood or other body fluids.

Major Scott Thomson describes the bacteriological examination of wounds treated with penicillin. "Exacting to handle and unstable though it may be," say Sir Howard Florey and M. A. Jennings, penicillin should not fail if it is given continuous contact with the tissues involved. This is the surgeon's problem and often it is not an easy one. The three main uses of penicillin, Lieut.-Colonel J. S. Jeffrey concludes, are to prevent infection soon after the infliction of the wound (in the forward areas), to control it during the first two weeks (at the forward base hospitals) and to combat infection in the later stages. The routine use of penicillin, he says, saves lives and minimizes functional disability and loss of manpower; it allows more rapid healing than has been possible before. It may therefore be especially useful, as Major-General L. T. Poole points out, to airborne troops, who may have to wait some time before the main forces fighting towards them can evacuate their wounded.
Future work, says Major-General Poole, will seek corroboration of the results already obtained and will tackle the problems which this work has raised. For this the continuation of the existing collaboration of chemists, pathologists, bacteriologists, clinicians and surgeons will be required. The collaboration here recorded between British and United States workers reminds us of the debt we also owe to others in the United States who have helped British workers to produce penicillin in such quantities that we can all now share its benefits. In Great Britain this debt is freely acknowledged. It is but one more instance of that co-operation of the English-speaking peoples which has done so much all over the world for the control of all kinds of human disease.

Since the above was written, a number of articles on penicillin have appeared which are related to several of the points mentioned.

The Lancet (348, Sept. 9, 1944), in a valuable annotation on penicillin, discusses the production of penicillin and the regulations which now control the manufacture of penicillin crude filtrate, dried crude filtrate and purified penicillin in the form of its sodium salt, and the good results which have been obtained with crude filtrates. The new regulations do not prevent any hospital from preparing penicillin for its own use. The Lancet refers to the full account of the preparation and properties of crude penicillin given by A. M. Fisher (Bull. Johns Hopkins Hosp., 73,$343 ; 1943$ ). In the same issue (page 336), I. W. J. McAdam, J. P. Duguid and S. W. Challinor describe the types of apparatus for continuous or three-hourly administration of penicillin. G. V. Osborne (The Lancet, 407, Sept. 23, 1944) describes an apparatus for administration by continuous ultra-muscular drip. Dr. C. A. St. Hill (Brit. Med. J., 631, Nov. 11, 1944) describes an apparatus, easily made from routine pathological equipment, for subcutaneous or intramuscular administration of penicillin to infants and young children.

The 'mega unit' of penicillin, which represents a million Oxford units, is discussed in The Lancet (522, Oct. 21, 1944); it is used only for ordering supplies in order to obviate the necessity of writing out hundreds of thousands of Oxford units and confusion with the American billion, which is only a thousand million. The international uniform standard and unit of penicillin agreed upon at the recent conference of the Health Section of the League of Nations are described in the British Medical Journal (572, Oct. 28, 1944, and The Lancet, 574, Oct. 28, 1944).

Lieut.-Colonel J. W. Bigger (The Lancet, 497, Oct. 14, 1944 ; see also p. 508) has described a method of alternately giving and withholding penicillin for infections with Staphylococcus pyogenes, based on his view that penicillin acts on bacteria at the time of their division and also actually kills staphylococci. A. M. Fisher (loc. cit. ; see also The Lancet, 348, Sept. 9 , 1944) found that it is bactericidal to $S$. aureus. Lieut.-Colonel Bigger believes that the few staphylococei which survive the penicillin do so because they are in a non-dividing phase. $\mathrm{He}$ calls them 'persisters', and his method aims at killing them when the penicillin treatment is recommenced.

W. McKissock, V. Logue and I. Bartholomew (Brit. Med. J., 551, Oct. 28, 1944), reporting on the local penicillin treatment of battle wounds of the head, emphasize the need for asepsis.

In view of the desirability of finding some method of slowing down the rapid excretion of penicillin, the work done by K. H. Beyer and his colleagues (Science, 
100, 107 ; 1944 ; see The Lancet, 542, Oct. 21, 1944), which indicates that intravenous administration of $p$-amino-hippuric acid delays the renal excretion of penicillin, merits further trial.

Lieut.-Colonel Bigger (The Lancet, 400, Sept. 23, 1944) claims that penicillin is, contrary to the statement made about it by many writers, inactivated by human blood or serum. The degree of inactivation varies, however, considerably with different specimens of serum and is much greater at body temperature than at lower temperatures. It may lead the bacteriologist to under-estimate the amount of penicillin in the serum of a patient, particularly when the concentration is low. Inactivation in vivo is probably chiefly important in cases in which the excretion by the kidneys is slow. The author, discussing the fact that penicillin is excreted chiefly by the kidneys, refers to Sir Howard Florey's comparison of the struggle to maintain an adequate concentration of penicillin in the blood to efforts to fill a bath while the plug is out. If, Colonel Bigger says, penicillin is constantly being inactivated by the plasma, we should add to this comparison a running cold tap and, in view of the difficulties of supply, a boilerman highly conscious of the need for fuel economy. The author also discusses the work of C. H. Rammelkamp and S. E. Bradley (Proc. Soc. Exp. Biol. and Med., 53, 30; 1943), who found that the administration of 'Diodrast' (B.P. diodone) delays the excretion of penicillin.

Marie Kalisova (Brit. Med. J., 597, Nov. 4, 1944) describes "the dramatic effect of penicillin on what would otherwise have been a hopeless case of acute appendicitis" in a child aged four. The penicillin was introduced directly into the peritoneal cavity, and by repeated aspirations of exudate from this cavity and its replacement by penicillin the patient's condition improved and his life was saved.

G. LAPAgE.

\section{ANTISEPTICS}

T HE first Lister Memorial Lecture of the Society of Chemical Industry was delivered on November 9 by Sir Alexander Fleming, of St. Mary's Hospital, London, at the University of Edinburgh; the title of Sir Alexander's address was "Antiseptics".

Lord Lister, in his epoch-making work, used carbolic acid as an antiseptic in surgery. This had the advantage of attacking all microbes equally, but the disadvantage of being poisonous to man and of destroying the leucocytes or white corpuscles of the blood which themselves act as the chief weapon in the body's own antiseptic armoury. The latest antiseptics, on the contrary, have a much greater effect against certain bacteria but are less destructive to leucocytes; the antibacterial to antileucocytic ratio of penicillin is 250,000 , of sulphanilamide 1,000 , but of carbolic acid only $\frac{1}{2}$.

Sir Alexander Fleming described his discovery of penicillin in 1929. There had been nothing in the literature to make anyone suspect that a substance with the chemical constitution of penicillin would have antibacterial value. The discovery had to come by chance, and it was his good fortune that the chance had presented itself to him. While working on quite a different subject he noticed that a mould (later proved to be Penicillium notatum), growing as a contamination on a culture plate, made a noteworthy change in co'onies of staphylococei on the plate. Thanks to his long interest in antiseptics and to his previous discovery of the natural antiseptic, lysozyme, Sir Alexander kept the plate for examination instead of throwing it away as many bacteriologists must have done before. The lapse of ten years between his discovery of penicillin and its preparation in a concentrated form suitable for therapeutic trial by the Oxford workers was due to the difficulty of concentrating and purifying it. This was a chemical problem. He himself was a bacteriologist.

It is calculated that pure penicillin, even if diluted to $\mathrm{I}$ in 50 million or more, will inhibit the growth of staphylococci, the common microbe of boils and carbuncles. On the other hand, it is so non-poisonous that, so far as Sir Alexander is aware, no one has yet had enough to poison a man. Like the sulphonamides, it is very specific, affecting certain microbes but having little or no action on others. It seems unlikely that we shall ever get an antiseptic which will affect all microbes without being poisonous to some human cells, but we shall have to arm ourselves with a series of chemicals covering the whole range of microbic growth. This will make it more diticult for the medical man; he will have to pay more attention to bacteriology than heretofore.

Penicillin is not perfect. For one thing, it is so rapidly destroyed in the stomach that it cannot be given by the mouth. There is still scope for the chemist to synthesize it, and then tinker with the molecule so that the imperfections can be remedied. There are thousands of other micro-organisms which may be capable of manufacturing even better antiseptics than penicillin, or ones which might give a clue to the chemical linkages responsible for the destruction of bacteria. The work is not finishedit is just beginning -and it is for the chemists now to carry it further.

\section{THE SCOTS PINE (Pinus sylvestris) By ALEXANDER L. HOWARD}

I remember, I remember,

The Fir-tree dark and high.

I used to think their slender tops

Were close against the sky.

Thomas Hood.

$T$ HIS tree, which is often incorrectly called 'fir' or 'Scotch fir', is a native of Britain, and the most important of our coniferous trees. From earliest days magnificent pine forests have grown in the Scottish Highlands where, as the Rev. C. A. Johns says, the seeds have been carried far and wide by the violent winds which are prevalent in that country, and also by rooks who are "Nature's planters of Pine Woods".

\section{Gerard (1545-1612) speaks of these trees as}

"growing in Cheshire, Staffordshire, and Lancashire where they grow in great plentie, as is reported before Noah"s floud, but then being overflowed and overwhelmed, have been since in the mosses and waterie moorish grounds, very sound and fresh until this day; and so foll of resinous substance that they burn like a torch or linke, and the inhabitants of those countries do call it Firre Wood and Fire woode unto this day."

Some people consider the Scots pine an uninterest. ing tree, and it is true that when reared under modern conditions in regular rows the conventional habit of its growth is apt to destroy its decorative value. 